\title{
3D City Models as a Visual Support Tool for the Analysis of Buildings Seismic Vulnerability: The Case of Lisbon
}

\author{
Paula Redweik $^{1} \cdot$ Paula Teves-Costa $^{1} \cdot$ Inês Vilas-Boas $^{2} \cdot$ Teresa Santos $^{3}$
}

Published online: 21 September 2017

(C) The Author(s) 2017. This article is an open access publication

\begin{abstract}
D city models associate a database of a city to a rigorous geospatial representation that is close to the visible reality by combining appearance, geometry, and semantics. As such, these models may include tools that convey attribute analysis, not only at the statistical level but also in terms of visual appearance of the objects, thus allowing the generation of new knowledge about a phenomenon or its effects. Lisbon is a city with a moderate level of seismic risk, and has been hit in the past by strong earthquakes. Several seismic vulnerability studies of buildings have been carried out in Lisbon. These studies generate different scenarios that consider the magnitude and source location of potential earthquakes. The results of these studies were presented as maps obtained from crossing information contained in 2D layers and presented in a GIS environment. In the present study a seismic vulnerability assessment of Lisbon's buildings held in $2 \mathrm{D}$ is extended to the third dimension, which refines the resolution and the set of parameters and explores the gains of spatial analysis in 3D representations. The numerous parameters that contribute to assess seismic vulnerability of buildings may be analyzed individually or simultaneously as well as in multiple seismic scenarios. Although covering all residential buildings in Lisbon, the application of the 3D
\end{abstract}

Paula Redweik

pmredweik@fc.ul.pt

1 Instituto Dom Luiz, Faculdade de Ciências, Universidade de Lisboa, 1749-016 Campo Grande, Lisbon, Portugal

2 ESRI Portugal, R. Julieta Ferrão 10, 1600-131 Lisbon, Portugal

3 CICS.NOVA - Centro Interdisciplinar de Ciências Sociais, Faculdade de Ciências Sociais e Humanas, Universidade Nova de Lisboa, Av. de Berna, 1069-061 Lisbon, Portugal city model is demonstrated with more detail in three pilot areas.

Keywords 3D-GIS · 3D models $\cdot$ Building vulnerability $\cdot$ Lisbon $\cdot$ Seismic scenarios

\section{Introduction}

The inherent weakness of a city to certain aspects of its environment that are susceptible to damage defines its vulnerability. This risk exposure is due to both social and physical characteristics as well as to urban morphology and infrastructure (Rashed and Weeks 2003). Vulnerability analysis is required to determine the level of this urban risk, which in turn indicates the degree of potential loss at each site due to a specific hazard. Risk arises as the product of the probability with which the hazardous phenomenon of a certain magnitude occurs multiplied by the degree of vulnerability (risk $=$ hazard $\times$ vulnerability). Thus vulnerability, unlike risk, is independent of the degree of hazard. It depends, instead, on the context in which the hazard occurs and includes both physical and social conditions (Rashed and Weeks 2003).

For a certain hazard, situational awareness is one of the most important factors in decision making (Zlatanova 2008), either before an event, based on planning simulations and preventive measures, or immediately after a disaster event through effective emergency management. Also later during the disaster recovery phase, when the verification and recording of damage and planning of mitigation solutions is most important, situation awareness is an absolute requisite.

Each type of hazard affects urban areas and their structures differently. When dealing with the phenomenon 
of seismicity, urban vulnerability depends on many factors that have a dynamic character in space and time. Variables that affect vulnerability to seismic events can be generally classified as physical (soil geology, topography, ground cover, type of construction, and so on) and social factors (average household income, average age of inhabitants, and other parameters). In most cases, both physical and social factors are likely to be represented in 2D maps, which can be used for spatial analysis in Geographic Information Systems (GIS) as presented, for instance, in Teves-Costa and Barreira (2012) for the city of Lisbon and in Rezaie and Panahi (2015) for the city of Tehran.

Development of 3D city models (3DCM) in this study, as support for urban risk management, follows the conclusion drawn by several authors (Kemec et al. 2009, 2010; Zlatanova 2008): 3D graphical representations embody a means of communication that is even more effective than the 2D maps already commonly used in studies of vulnerability, hazard, and risk. 3D views significantly reduce the cognitive effort necessary to interpret data and analysis results, which improves the efficiency of the decisionmaking process by national and municipal authorities (Kemec et al. 2009). Showing citizens the urban environment from a perspective close to everyday reality increases risk awareness, which may have positive (alert for taking preventive measures) or negative (alarmism, depreciation of certain property, localized increase of insurance premiums) consequences. Kemec et al. (2010) developed a 3D city model to support risk management in case of an earthquake. This model elaborated the most suitable data resolution and representation detail for such an application from the point of view of the developer, but left the exploitation of the model for further development.

One of the urban elements that most influences the degree of seismic vulnerability of a city is the quality of the building stock (typology, design, age, and conservation state of the buildings). Urban infrastructure, both above and below ground, is as much or more vulnerable than buildings, since the cascading effects associated with damaged infrastructure will ultimately affect structures that originally were not directly destroyed by the earthquake. An interesting study about the seismic vulnerability of interconnected infrastructure is presented by Poljansek et al. (2010). A common property of these elements, buildings and infrastructure, is their three-dimensional geometric development. The present study focuses on the vulnerability of residential building stock, which is determined at building scale according to the RISK-UE LM1 methodology (Milutinovic and Trendafiloski 2003), and relies on the $3 \mathrm{D}$ representation of variables, results and seismic scenarios using a specially generated 3DCM.

In order to create a 3DCM to suit a certain goal, a set of constraints must be defined. In addition to the Level of
Detail (LoD) that defines the level of accuracy with which the elements should be represented in the 3DCM, the classes of elements to include in 3DCM, and the geospatial extension of the model also must be defined. All of these factors must be subordinated to the concrete objective of the model and to the target public that will explore it. Dependent on these preconditions, the geometric data and attributes are collected in accordance with the objective. The geometric and semantic modeling of elements is the next step; this level of model construction uses geometric primitives and data models either established or adapted to the objective in question. The process comes to an end with the model exploitation phase. This phase may involve passive viewing and navigation in the model, but also can incorporate the user's interaction, such as the ability to perform spatial analysis and to compare several scenarios, which has to be made possible in order to gain new knowledge from the geometrically and semantically modeled data.

The seismic vulnerability of residential buildings in Lisbon was calculated and several seismic scenarios were analyzed. The advantages of the use of 3DCM are exemplified in three pilot areas chosen for their different characteristics. In this article, the methodology and the study's conditioning parameters are presented and the results obtained as well as the corresponding analysis are discussed. As tools, ArcGIS Desktop 10.3 (ESRI 2017), ArcGIS Pro (ESRI 2017), CityEngine 2015.1 (ESRI 2017), CityEngine Web Viewer (ArcGIS 2017), and Portal for ArcGIS Server (ESRI 2017) from Environmental Systems Research Institute (ESRI) were used as well as Matlab R2015 from Mathworks. ${ }^{1}$

\section{Definition of the 3D City Model in the Study}

The constraints of the study and the aspects considered in their definition are as follows:

1. Objective of the 3DCM: The model is intended to enable development of a seismic vulnerability study of the buildings of a city that shows the geometry of the buildings, their geographic position, and their relationship to their immediate neighborhood, as well as to construct a database that includes seismic vulnerability-defining parameters at building scale;

2. Target audience: Experts, elected officials, planners, civil protection agents, and those individuals and agencies involved in emergency response; eventually common citizens should be considered as target audience in the context of risk awareness campaigns;

\footnotetext{
$\overline{1}$ https://www.mathworks.com/.
} 
3. Extension of 3DCM: Area of the municipality of Lisbon $\left(85 \mathrm{~km}^{2}\right.$ ). Three pilot areas (about $0.25 \mathrm{~km}^{2}$ each) are addressed with more detail;

4. Elements to include: Elements at risk to consider in the study and framing elements are: (a) ground; (b) buildings with spatial and vulnerability attributes; and (c) streets with spatial attributes. Underground roads (in tunnels) are not considered; and

5. Level of detail: To define the level of detail it is necessary to consider several aspects that will be addressed in the paragraphs that follow.

The authors adopted the scale and detail levels of CityGML (2017) that have been widely implemented in the field of 3D modeling. CityGML is an open standard of the Open Geospatial Consortium (OGC) for 3DCM encoding in which five levels of detail are defined, from LoD0 to LoD4 in ascending order of spatial detail and geometric precision of the data. To choose the adequate LoD for this study, we employed the hierarchical decision rule utilized by Kemec et al. (2009) in the scope of disaster management. This rule decides the level to use based on eight decision-making criteria to which values on a scale are assigned, according to the characteristics of the study area and the hazard to be addressed. The criteria are grouped in an Analytic Hierarchy Process (AHP) decision tree: two elements of a spatial nature of the area under study (extension of urban area; population density), two aspects of the spatial nature of the hazardous event (spatial dispersion; affected area), three characteristics of the temporal nature of the hazard (speed of onset; duration; frequency), and a single criterion that is related to the penetration into a building's interior space of hazardous material caused by the event under investigation. For example, floods and avalanches invade the interior of buildings with external material; earthquakes, by themselves, according to the referenced authors, do not. The interpretation of the indoor penetration criterion may be questionable, since shock waves produced by earthquakes do invade a building's interior rupturing walls and leave debris behind. On the other hand, this fact is independent of the existence of windows or doors and of the configuration of interior walls in the 3D model. So we adopted the interpretation of the cited authors, since the consideration of indoor penetration only influences the decision of modeling openings and interiors, which is not important in the present case.

Although the scale to be assigned to the first seven criteria goes from 1 to 5 , the eighth criterion is of binary nature, having only values of 0 (nonpenetrating) or 1 (penetrating). The meaning of the values of the scale of $1-5$ is different for each of the criteria and is explained in Tables 1 and 2.
Table 1 Classes and scale for criteria $a_{\mathrm{ue}}$ and $p$

\begin{tabular}{llll}
\hline Urban extension (ha) & $a_{\text {ue }}$ & Population density $($ pers/ha) & $p$ \\
\hline $200<$ area $\leq 648$ & 1 & $0.12<$ dens $\leq 0.45$ & 5 \\
$648<$ area $\leq 2104$ & 2 & $0.45<$ dens $\leq 1.61$ & 4 \\
$2104<$ area $\leq 6824$ & 3 & $1.61<$ dens $\leq 5.75$ & 3 \\
$6824<$ area $\leq 22,136$ & 4 & $5.75<$ dens $\leq 20.54$ & 2 \\
$22,136<$ area $\leq 71,800$ & 5 & $20.54<$ dens $\leq 73.28$ & 1 \\
\hline
\end{tabular}

The classes for "extension of urban area" $\left(a_{\text {ue }}\right)$ and "population density" $(p)$ were defined according to a study on urban regions based on the 2001 census data for Portugal from the Instituto Nacional de Estatística (INE 2004)—National Statistics Institute. Although no similar study was available for the 2011 census, we assumed that eventual evolution occurred in the urban centers on what concerns area and population would not be much reflected in the coarse classification needed for this work. The area and population density of urban centers were classified in geometric intervals. Lisbon presents an area of 8500 ha and a population density of 66.43 persons/ha, so the respective values for attribute $a_{\mathrm{ue}}$ is 4 and for attribute $p$ is 1 . The values assigned to each criterion describing the hazard under study for the present case-Lisbon and seismic hazard-can be seen in Table 2 .

The decision rule requires the calculation of the intensity value $I_{\mathrm{v}}$ by Eq. 1 . This was first applied to the attribute values shown in Table 2, and then normalized by Eq. 2 to obtain $I_{\text {vnorm }}$. Equation 3 calculates results for the value of D, which defines the LoD (D) to be applied in our study's 3DCM. Except for population density, the attributes scale of each criterion is defined incrementally according to the degree of predominance. The logic behind this definition is that higher $I_{\mathrm{v}}$ values indicate a pervasive situation that requires little spatial detail, while lower $I_{\mathrm{v}}$ values indicate one intense situation that requires models with more spatial detail (Kemec et al. 2009). The orientation of the scale for population density, with lower values for higher densities leading to lower values of $I_{\mathrm{v}}$ in this case, indicates a need for more model detail in densely populated areas.

$I_{\mathrm{v}}=\left[\left(\left(\frac{s_{0}+d+f}{3}\right)+\frac{\left(\frac{s_{\mathrm{d}}+a_{\mathrm{e}}}{2}\right)}{2}\right) \times\left(\frac{a_{\mathrm{ue}}+p}{2}\right)\right]$

$I_{\mathrm{vnorm}}=\operatorname{round}\left(\frac{I_{\mathrm{v}}-I_{\mathrm{vmax}}}{I_{\mathrm{v} \min }-I_{\mathrm{vmax}}}\right) \times 4$

$D=I_{\mathrm{vnorm}}+i / 2$

The values obtained in the present case are $I_{\mathrm{v}}=7.083$, $I_{\text {vnorm }}=1$, resulting in $D=1$. That means, for the study of the seismic vulnerability of the buildings for the whole city 
Table 2 Values assigned to decision criteria dependent on Lisbon earthquake hazard

\begin{tabular}{llll}
\hline Criterion & Symbol & Scale description & Attribute value \\
\hline Frequency & $f$ & Frequent (5) to rare (1) & 2 \\
Duration & $d$ & Long (5) to short (1) & 1 \\
Speed of onset & $s_{\mathrm{o}}$ & Slow (5) to rapid (1) & 1 \\
Spatial dispersion & $s_{\mathrm{p}}$ & Large (5) to small (1) & 3 \\
Affected area & $a_{\mathrm{e}}$ & Extensive (5) to limited (1) & 3 \\
Penetration inside & $i$ & Penetrating (1), nonpenetrating (0) & 0 \\
\hline
\end{tabular}

of Lisbon, a 3DCM with LoD1 would be appropriate. For a smaller area, for example, limited to a parish of medium size, the attribute for the criterion $a_{\text {ue }}$ would be 1 and, keeping the values for all other attributes, the resulting $D$ value would be equal to 3 , meaning that much more detail is required. In LoD1, buildings are represented only by geometric blocks (prisms) with the corresponding height, but no other details. Whereas in LoD3 roofs are already modeled with their actual shape, the openings in facades (windows, balconies) are also shaped, as well as all associated facilities such as outdoor stairways, elevator accessories on the roof, and so on. As recommended by the decision rule, LoD1 was used in this study for the whole city, although with some improvements, and, for the pilot areas, the representation was consistent with LoD2 with some models in LoD3/4.

\section{Methodology}

In this section the workflow of the study is presented as well as the sources for input data. Further, the used method for calculating the vulnerability index for each building and the respective damage degree in several seismic scenarios is presented. Finally, the 3D modeling of the buildings with several appearances and the constraints and advantages of web publishing are addressed.

\subsection{Workflow}

Figure 1 shows the implemented workflow. Input data for each study unit, the residential building, were gathered in a shapefile (ESRI 2017) linked to the respective 2D footprint in ArcGIS/ArcMap (ESRI 2017). New fields of the attribute table were calculated as simple functions of the input attributes or retrieved from ArcMap functions, such as building height or terrain slope. Matlab scripts were developed for the calculation of all the additional fields corresponding to parameters of vulnerability. Results were directly saved in the shapefile yielding a global

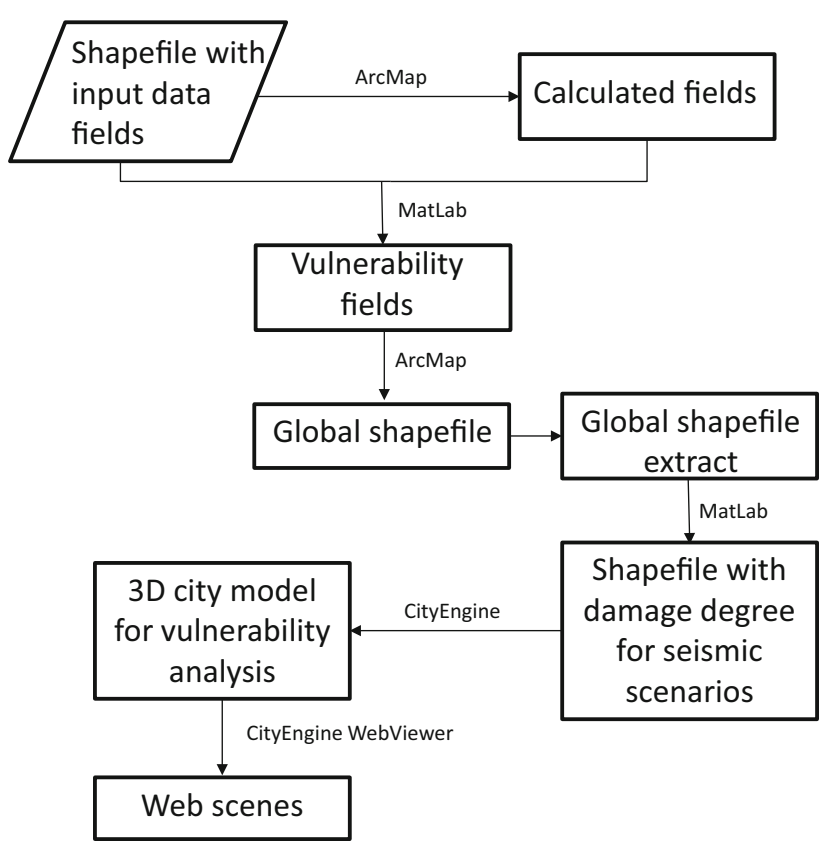

Fig. 1 Workflow for the 3D city modeling

vulnerability file with all attributes of the buildings, from which an extract was taken to calculate the damage degree according to several seismic scenarios. This operation was also performed through a Matlab script. The shapefiles with the damage degrees for each building footprint in each scenario were entered in CityEngine (ESRI 2017) in order to generate the $3 \mathrm{D}$ city model. The $3 \mathrm{D}$ scenarios produced were first organized and then published on the Web or placed on a server to be exploited by target audience.

\subsection{Input Data}

Data for this study had several origins. From the building database of the municipality of Lisbon from 2009 acquired for a previous project from the Câmara Municipal de Lisboa $(\mathrm{CML})^{2}$ we obtained the $2 \mathrm{D}$ buildings' footprints, addresses, and the number of floors above ground for each

\footnotetext{
$\overline{2}$ http://www.cm-lisboa.pt/.
} 
building. To characterize the buildings by construction type and construction epoch, geolocated data from the Portuguese 2011 census were acquired from the Instituto Nacional de Estatística (INE 2011). Aerial photographs of Lisbon from several epochs (1947, 1978, and 2004) were analyzed to confirm, by photo interpretation, the classification from the census regarding the construction epoch of individual buildings. Photographs from 1947 were flown by the British Royal Air Force (RAF) and belong to sets acquired from Centro de Informação Geoespacial do Exército $(\mathrm{CIGeoE})^{3}$ for previous projects. The aerial photographs from 1978 were flown by the Força Aérea Portuguesa (FAP) and the ones from 2004 were flown by ERFOTO. They are also part of sets acquired for previous projects from the Direção Geral do Território (DGT). ${ }^{4}$ Landform data were obtained from a $5 \mathrm{~m}$ grid Digital Terrain Model (DTM) created from the contours of the 1:25,000 military topographic map from CIGeoE. Terrain geology classification was based on Almeida (1986). Geolocated information about abandoned buildings in the city of Lisbon originating from Santos et al. (2015) was also added. From Dias (2013), a 2.5D landfill map of Lisbon was attached to the input dataset. This data source identifies landfills created between 1944 and 2006. For the pilot areas, attributes such as roof type and relative position in the neighborhood came from aerial image interactive analysis. Facade textures were also included; these data were photographically obtained in field work.

\subsection{Building Vulnerability Indices}

For each building, seismic vulnerability was calculated following methodology LM1 of the RISK-UE project (Milutinovic and Trendafiloski 2003) that considers a total vulnerability index, $\bar{V}_{\mathrm{I}}$, calculated by Eq. 4 . In order to assign the most probable vulnerability index $\left(V_{I}^{*}\right)$ to a certain building, the pair type of construction/epoch of construction was used. This procedure took into consideration the classification assigned by Sousa (2006) for the building stock in Lisbon adapting the classes to those of RISK-UE. In addition, the regional vulnerability factor for Lisbon $\left(\Delta V_{\mathrm{R}}\right)$ was assumed to be 0.08 (Teves-Costa et al. 2011) and several behavior-modifying factors for each building $\left(\Delta V_{\mathrm{m}}\right)$ were considered according to the available data, which are described in Tables 3 and 4 . The building

\footnotetext{
${ }^{3}$ https://www.igeoe.pt/index.php?id=1.

${ }^{4}$ http://www.dgterritorio.pt/.
}

typology classification used in the present study is shown in Table 5.

$\bar{V}_{\mathrm{I}}=V_{\mathrm{I}}^{*}+\Delta V_{\mathrm{R}}+\Delta V_{\mathrm{m}}$

Additionally, as a new parameter, the consistency of the soil under the buildings was considered. Taking into consideration the existence of several landfills in Lisbon (Dias 2013), numerical simulations were performed to compute the transfer functions of these deposits (Teves-Costa et al. $2012,2014)$ in order to estimate their potential effect on building seismic response (Bakir et al. 2002; Navarro et al. 2012). From the computations it was observed that the effects of these superficial deposits are only significant when the deposits are more than $10 \mathrm{~m}$ thick and, due to their natural frequencies, for buildings with more than five floors. RISK-UE methodology proposes factors between +0.02 and +0.04 to take into account the settlement of the building on less favorable soil conditions (Milutinovic and Trendafiloski 2003). Consequently, a behavior modifying factor of +0.02 was assumed for buildings with more than five floors built on landfills that were more than $10 \mathrm{~m}$ thick.

\subsection{Damage Degree}

In order to simulate damage scenarios for an earthquake, it is necessary to estimate how building stock reacts according to the total vulnerability index assigned to each building, $\bar{V}_{\mathrm{I}}$, for a certain seismic intensity, $I$. An aggravation factor, $F_{\mathrm{A}}$, dependent on the location of the earthquake source and on the geology/lithology of the soil was also introduced. In this study two types of earthquakes were considered according to the most frequent epicenter locations in the seismic history of Lisbon: (1) the far source, corresponding to earthquakes with an origin at the Gorringe Ridge area in the Atlantic Ocean (about $270 \mathrm{~km}$ southeast from Lisbon); and (2) the near source corresponding to earthquakes originating in the Lower Tagus Valley fault system (the strongest of which had its epicenter about $40 \mathrm{~km}$ from Lisbon). The soils of Lisbon were classified in three types: rock, intermediate, and soft soil. The topography of the city is characterized by a relatively flat central zone, mostly located between 70 and $120 \mathrm{~m}$ high, which occupies about $64 \%$ of the city's area. The downtown area, located in the south-southeast, is surrounded by several small hills whose altitude can reach $110 \mathrm{~m}$. In addition, the city has a flat waterfront area and a forest area (not urbanized) located at an elevation that reaches $228 \mathrm{~m}$ height occupying about $11 \%$ of the city's area (Monsanto Forest Park). A slope map, based on the digital terrain model, shows that only $5 \%$ of the total area of the city has slopes higher than $10 \%$ (Teves-Costa et al. 2011). Taking into account that the local conditions (soil 
Table 3 Behavior modifying factors for masonry buildings. Source: Milutinovic and Trendafiloski (2003)

\begin{tabular}{lll}
\hline Behavior modifying factor & Parameters & $\left(\Delta V_{\mathrm{m}}\right)_{\mathrm{i}}$ \\
\hline Preservation & Good & -0.04 \\
& Bad & +0.04 \\
Number of floors & Low (1-2) & -0.02 \\
& Medium $(3,4$, or 5) & +0.02 \\
& High $(6$ or more $)$ & +0.06 \\
Building position in block & Middle $^{\mathrm{a}}$ & -0.04 \\
& Corner $^{\mathrm{s}}$ & +0.04 \\
& Header $^{\mathrm{b}}$ & +0.06 \\
\hline
\end{tabular}

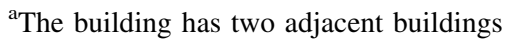

${ }^{\mathrm{b}}$ The building has one adjacent building (three free sides)

type and topography) can modify the characteristics of the seismic ground shaking (Borcherdt 1970; Idriss 1990), thus affecting the observed macroseismic intensity
(Giammarinaro et al. 2005; Fritsche et al. 2009; Navarro et al. 2009), an aggravating factor was introduced in the mean damage degree equation used in RISK-UE (Milutinovic and Trendafiloski 2003). This aggravating factor, presented in Table 6, varies from -0.25 to +1.5 , depending on the earthquake source, taking into account the combined effect of the topography and the geology (TevesCosta et al. 2011). The mean damage degree formula, modified from Milutinovic and Trendafiloski (2003), is presented in Eq. 5

$\mu_{\mathrm{D}}=2.5 \times\left[1+\tanh \left(\frac{I+6.25 \bar{V}_{\mathrm{I}}-13.1+F_{\mathrm{A}}}{2.3}\right)\right]$

The values for the resulting mean damage degree have been rounded in order to agree with the classification presented by Grünthal (1998) in the European macroseismic scale (EMS98), which describes 5 damage degrees for buildings ranging from 1 (light damage) to 5 (total collapse). This macroseismic scale was chosen due to the fact

Table 4 Behavior modifying factors for buildings of reinforced concrete (RC).Source: Milutinovic and Trendafiloski (2003)

\begin{tabular}{lll}
\hline Behavior modifying factor & $\left(\Delta V_{\mathrm{m}}\right)_{\mathrm{i}}$ & Middle level \\
\cline { 2 - 3 } & Pre-code or low level & 0 \\
\hline Seismic dimensioning code level & +0.16 & +0.02 \\
Bad preservation & +0.04 & -0.04 \\
Number of floors & & 0 \\
Low (1 to 2) & -0.04 & +0.06 \\
Medium (3, 4 or 5) & 0 & +0.08 \\
High (6 or more) & & + \\
\hline
\end{tabular}

Table 5 Seismic vulnerability according to the pair construction typology/construction epoch

\begin{tabular}{|c|c|c|c|c|}
\hline \multirow[b]{2}{*}{ Construction typology } & \multicolumn{2}{|l|}{ Sousa (2006) } & \multicolumn{2}{|c|}{ European project Risk-UE } \\
\hline & Construction epoch & Class & Designation & Seismic vulnerability index $\left(V_{\mathrm{i}}^{*}\right)$ \\
\hline Adobe, Stone & & A & M2 & 0.840 \\
\hline Other (Metalic) & & $\mathrm{E}$ & $\mathrm{S} 1$ & 0.363 \\
\hline \multirow[t]{4}{*}{ Masonry without RC floor } & Before 1919 & $\mathrm{~B}$ & M1.1 & 0.873 \\
\hline & $1919-1960$ & $\mathrm{~B}$ & M1.2 & 0.740 \\
\hline & $1961-1980$ & $\mathrm{C}$ & M3.4 & 0.616 \\
\hline & $1981-2011$ & $\mathrm{D}$ & M4 & 0.451 \\
\hline \multirow[t]{2}{*}{ Masonry with RC floor } & Before 1919-1980 & $\mathrm{C}$ & M3.4 & 0.616 \\
\hline & 1980-2011 & $\mathrm{D}$ & M4 & 0.451 \\
\hline \multirow[t]{6}{*}{ Reinforced concrete } & 1919-1960 & $\mathrm{C}$ & $\mathrm{RC} 1$ & 0.442 \\
\hline & $<8 \mathrm{Fl}$ & & & \\
\hline & 1961-1980 & $\mathrm{C}$ & $\mathrm{RC} 1$ & 0.442 \\
\hline & $>8 \mathrm{Fl}$ & & & \\
\hline & 1961-1980 & $\mathrm{D}$ & $\mathrm{RC} 2$ & 0.386 \\
\hline & 1980-2011 & $\mathrm{D}$ & $\mathrm{RC} 2$ & 0.386 \\
\hline
\end{tabular}


Table 6 Aggravation factor $F_{\mathrm{A}}$ according to earthquake origin, soil type, and slope

\begin{tabular}{llll}
\hline Earthquake source & Type of soil & $F_{\mathrm{A}}$ \\
\cline { 3 - 4 } & & Slope $<10 \%$ & Slope $>=10 \%$ \\
\hline Near & Rock & +0.5 & +1.0 \\
& Intermediate & 0 & +0.5 \\
& Soft & -0.25 & +0.25 \\
Far & Rock & 0 & +0.5 \\
& Intermediate & +0.5 & +1.0 \\
& Soft & +1.0 & +1.5 \\
\hline
\end{tabular}

that its use is recommended by the European seismological commission $(\mathrm{ESC})^{5}$ to evaluate the damages in European earthquakes. Besides, the building classification used in RISK-UE is also based on this scale.

\subsection{D Modeling and Web Publishing}

The database containing all the buildings with attributes, the respective vulnerability index, and the damage degree calculated for two different macro seismic intensities (VII and IX) for each earthquake source considered (far and near) was imported into CityEngine 2015.1 (ESRI 2017) to proceed with the $3 \mathrm{D}$ modeling and analysis of the results. Table 7 shows an overview of the database fields indicating which values were input and which were calculated. Additional fields could be introduced, for instance, to include the probability that a building would suffer damage of a certain degree or higher as a function of the seismic intensity (fragility of the building). In this case, five additional fields (one for each degree of the scale from 1 to 5 ) could be calculated for each seismic scenario. Although feasible, fragility was not explored in this study since probability values are not adequate for visual representation.

The 3D modeling was done by means of several Computer Generated Architecture (CGA) rules. These were implemented to automatically build the 3D geometry of each building from the footprint and respective geometric attributes (building height, roof type), and to provide each building with an appearance, which could vary between actual texture, symbolic colored texture, or damage realistic texture, according to the type of possible question addressed by the model (Fig. 2). In the last two alternatives, the color or aspect of the building depends on the respective seismic attributes, such as damage degree or vulnerability index class.

Since the intention of the study was to produce layers that could be exploited through the Web by stakeholders,

\footnotetext{
5 http://www.esc-web.org/.
}

the query dynamic is limited to the capacities of the used Web viewers. It was not possible to publish only one 3D scene with several appearances for each object, since appearances are not queryable (not included as attributes in the database). Therefore, several 3D scenes had to be created for each study area in order to answer the most common demands of the target audience. This audience can be grouped in three categories:

1. Experts, elected officials, and planners, who consult the 3D model as analysts, want to know, for instance, how many masonry buildings exist in a certain city district or how old is the building stock. For this kind of questions, a layer with the 3DCM of the district with actual texture appearance is sufficient. This layer contains the attributes of the buildings independent of seismic scenarios. Other questions, such as "how vulnerable is the neighborhood?" or "how does the urban morphology (directly observable in the 3D model) influence the earthquake scenario?" are best answered in color symbolized layers: the first query is dealt with according to vulnerability classes and the second inquiry is answered using the damage degree scale. Experts can also use color symbolized layers to test the sensitivity of damage scenarios to vulnerability parameters.

2. Civil protection agents and those involved in emergency response, who will consult the 3D model as a simulation tool for planning actions in advance of a seismic event or immediately after. This group will analyze the damage scenarios with color symbology and, perhaps, compare them with the actual texture model for orientation; and

3. Citizens in the frame of awareness campaigns, who are likely to explore the model looking for an intuitive answer to questions such as "what will happen to my building or my neighborhood in case of an earthquake?" or "how high is the vulnerability level on the site where I live?" This group tends to look for the "big picture" and is not searching for attributes and it is this general public that is the target for the damage realistic textured layer that is addressed later in this work.

The 3D model with actual texture and the set of damage scenarios is published on the Web and presented as separate layers for the user to choose. Because of the dimension of the models, the pilot areas are published in ArcGIS online, accessible in a CityEngine Web Viewer with several possibilities of visualization, navigation, querying, and comparison of layers. This mode also allows some interaction between the user and the model by means of localized comments. The whole city, on the contrary, is published via a local server through a Portal for the ArcGIS 
Table 7 Vulnerability database fields

\begin{tabular}{|c|c|c|}
\hline Field name & Description of attribute & Origin \\
\hline COD_SIG & Code in the database of the municipality of Lisbon & Input \\
\hline BGRI11 & Code in INE database & Input \\
\hline ID & Building identifier & Input \\
\hline Freguesia & Parish & Input \\
\hline Morada & Street & Input \\
\hline Nr Polícia & Number & Input \\
\hline Nr Pisos & Number of floors & Input \\
\hline Int Pisos & Floor interval & Input \\
\hline Altura Edi & Building height & Input \\
\hline Tipo Const & Construction type & Input \\
\hline Épo Const & Construction epoch & Input \\
\hline Classe Vul & Building vulnerability class based on pair type/epoch of construction & Calculated \\
\hline Ind Vuln & Building vulnerability index based on pair type/epoch of construction & Calculated \\
\hline Tipo telha & Roof type & Input \\
\hline Era & Geology of the soil—age & Input \\
\hline Período & Geology of the soil-period & Input \\
\hline Época & Geology of the soil-epoch & Input \\
\hline Código & Code for soil type identification & Input \\
\hline Categ Solo & Soil type & Input \\
\hline Descrição & Description of soil type & Input \\
\hline F Agrav Af & Aggravation factor for far source earthquake & Calculated \\
\hline F Agrav Pr & Aggravation factor for near source earthquake & Calculated \\
\hline Decl Grau & Slope (in degrees) & Calculated \\
\hline Decl Perc & Slope (in percentage) & Calculated \\
\hline Aterro & Landfill depth & Input \\
\hline Solo Alter & Significance of landfill & Calculated \\
\hline Estado & Abandoned or inhabited & Input \\
\hline Manutenção & Maintenance state & Input \\
\hline Ind Fund & Foundation vulnerability index & Calculated \\
\hline F Regional & Regional vulnerability factor & Input \\
\hline Ind Pcode & Seismic dimensioning code & Input \\
\hline Ind Pisos & Floors vulnerability index & Calculated \\
\hline Ind Manut & Maintenance vulnerability index & Calculated \\
\hline Ind Pos & Position in block vulnerability index & Calculated \\
\hline VI & Total vulnerability index & Calculated \\
\hline uNearVII & Mean damage degree (near source-intensity VII) & Calculated \\
\hline uNearIX & Mean damage degree (near source-intensity IX) & Calculated \\
\hline uFarVII & Mean damage degree (far source-intensity VII) & Calculated \\
\hline uFarIX & Mean damage degree (far source-intensity IX) & Calculated \\
\hline
\end{tabular}

Server that provides access to a large amount of data, but does not possess the same ability (as the CityEngine Web Viewer) to explore the model and the information layers. Both alternatives can be accessed via the Web through a link shared with the stakeholder, without the need of any software installation.

Queries are introduced in the Web Viewer as attribute searches in the database, for instance, Type_Const: Masonry. As an answer, all the buildings with construction type Masonry will be highlighted in the 3D viewer and a count of occurrences will be shown (Fig. 3). In addition, a list of the buildings matching the search criterion is also shown.

Once the layer is on the 3D viewer, all building attributes are accessible by selecting one of the buildings either in the $3 \mathrm{D}$ viewer or in the list; the user can analyze the eventual relation between damage degree and construction epoch by highlighting the buildings from a particular epoch 


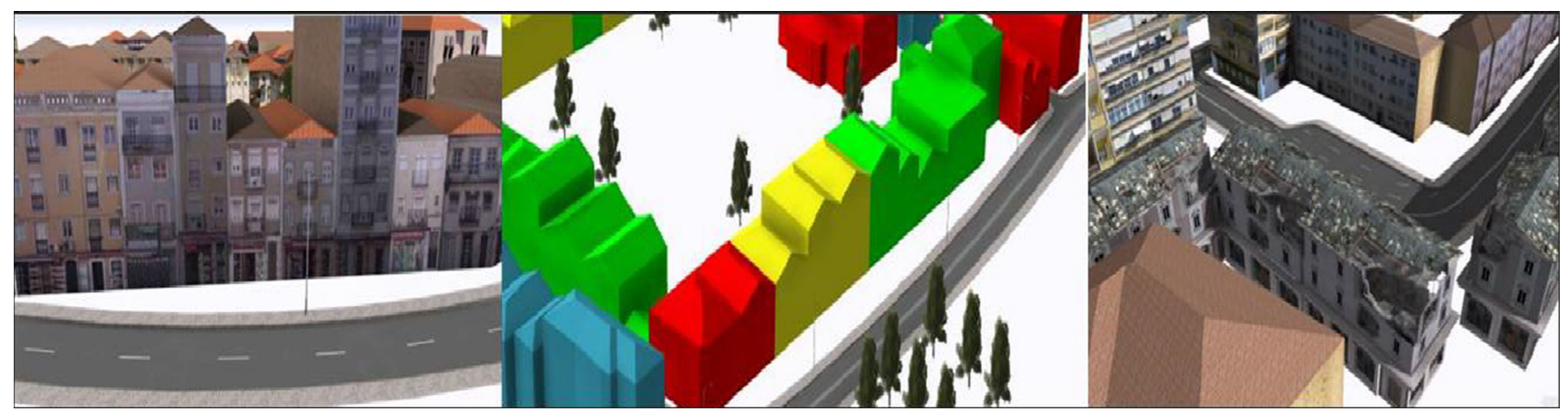

Fig. 2 Appearance of buildings in 3D model according to query context: actual texture (left); colored symbology (middle); damage realistic texture (right)

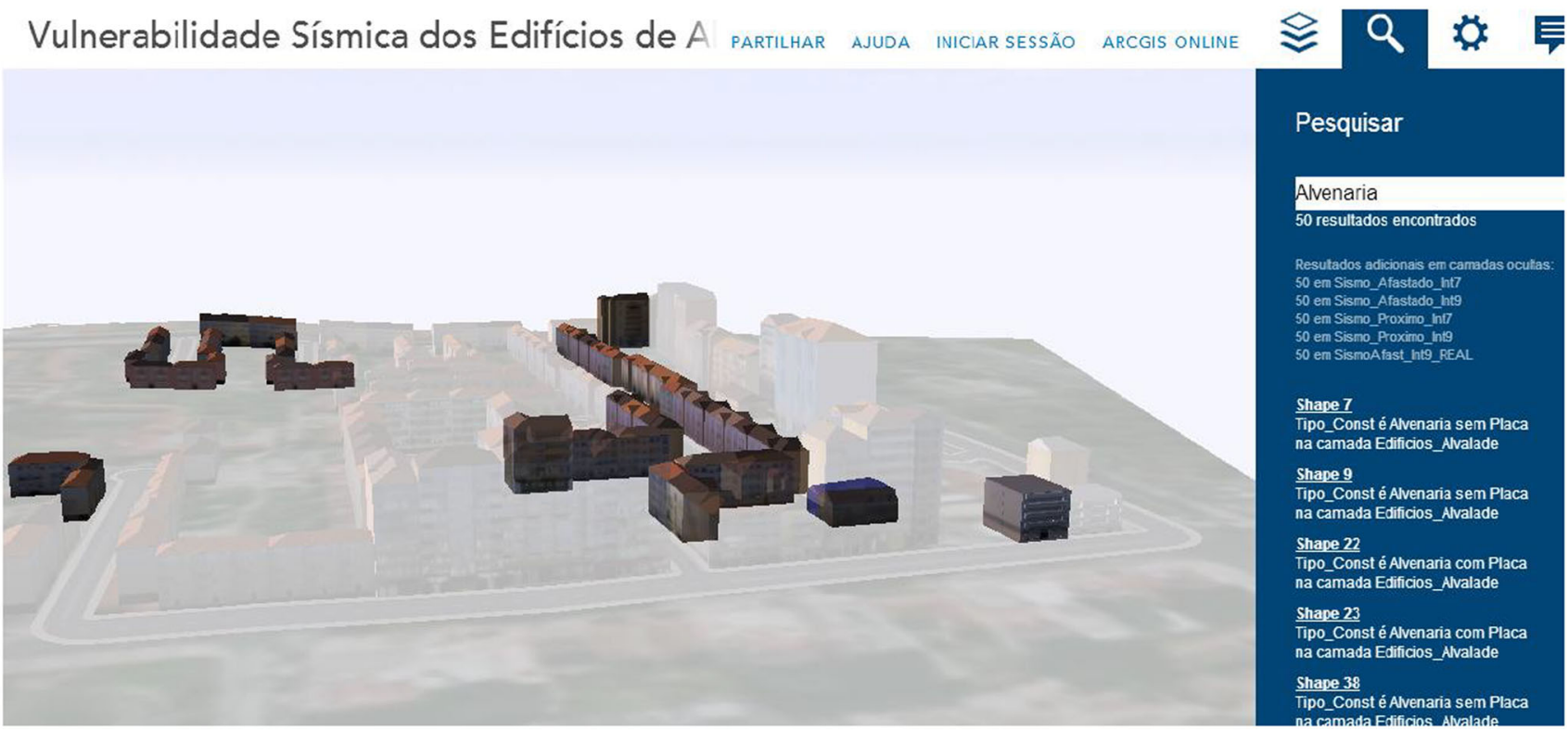

Fig. 3 CityEngine web viewer layout example: result of the query "Type of construction: Masonry-Alvenaria (in Portuguese)" for the pilot area Alvalade; (left) highlighted buildings in 3D scene matching

in a layer where they are colored according to the damage scale. Although in the studied example only four seismic scenarios were simulated corresponding to four different layers, a number of other scenarios can be produced for other intensities and earthquake sources as long as the respective values for the aggravation factor, $F A$, are estimated and introduced into the scripts.

\section{Results}

After applying the proposed methodology to the gathered data, a 3D seismic vulnerability model was built for the whole city of Lisbon and for three smaller areas. Some examples of how new knowledge can be retrieved from the built models are presented in this section. the criterion; (right) search criterion, amount of buildings matching the criterion (50), and respective list (excerpt)

\subsection{Estimated Damage for Residential Buildings in Lisbon}

At a city scale, because the 3D model is explored by users for acquaintance with the general situation or analysis of vertical morphology distribution, the realism of textures was not considered a priority. Generic facade textures were arbitrarily assigned to the buildings in the layer corresponding to the actual situation of the whole city (Fig. 4). Due to the extension of the model it had to be processed in another software, ArcGIS Pro, using imported CGA rules that had been programmed in CityEngine. Unfortunately, this software, although able to cope with more data, does not offer the same graphic quality as CityEngine.

Four seismic scenarios were simulated: two near sources-intensity VII and IX and two far sources-intensity 


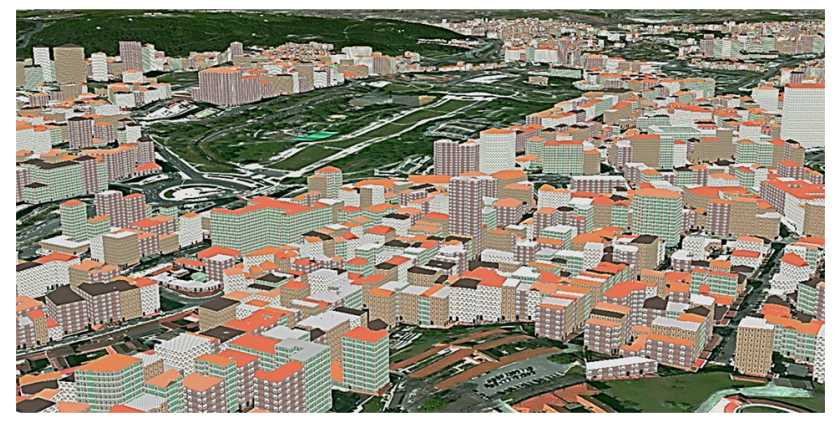

Fig. 4 3D model of Lisbon with actual situation appearance (generic facade textures)

VII and IX. The probable damage degree, according to the total vulnerability index of each of the 52,374 habitation buildings in Lisbon municipality, was computed and represented visually. In the layers corresponding to seismic scenarios, buildings conserved the 3D geometry but were assigned a solid color appearance that matched the respective damage degree. A discrete color scale with 6 steps was adopted, corresponding to the EMS98 damage degrees: blue (degree 1), green (degree 2), yellow (degree
3), red (degree 4), dark red (degree 5-total collapse), and light blue for no damage.

Figure 5 shows the resulting spatial distribution of damage for the scenarios considered. A good general panoramic of the areas expected to be more affected can be obtained from these scenarios. Intensity IX from a far source earthquake corresponds to the situation that occurred in 1755. The model shows that the most affected areas then would also be the most affected now, with a total collapse of most buildings in downtown and a large surrounding area experiencing damage degree 4 . Table 8 shows the number of affected buildings according to damage degree and seismic scenario.

\subsection{Deeper Analysis in Pilot Areas}

Pilot areas were chosen for detailed modeling and inclusion of additional behavior-modifying factors. The selected areas are representative of city districts in their construction epoch, soil geology, and urban morphology. Due to the 1755 earthquake that devastated the city, there are only a few structures that date from before the eighteenth century.
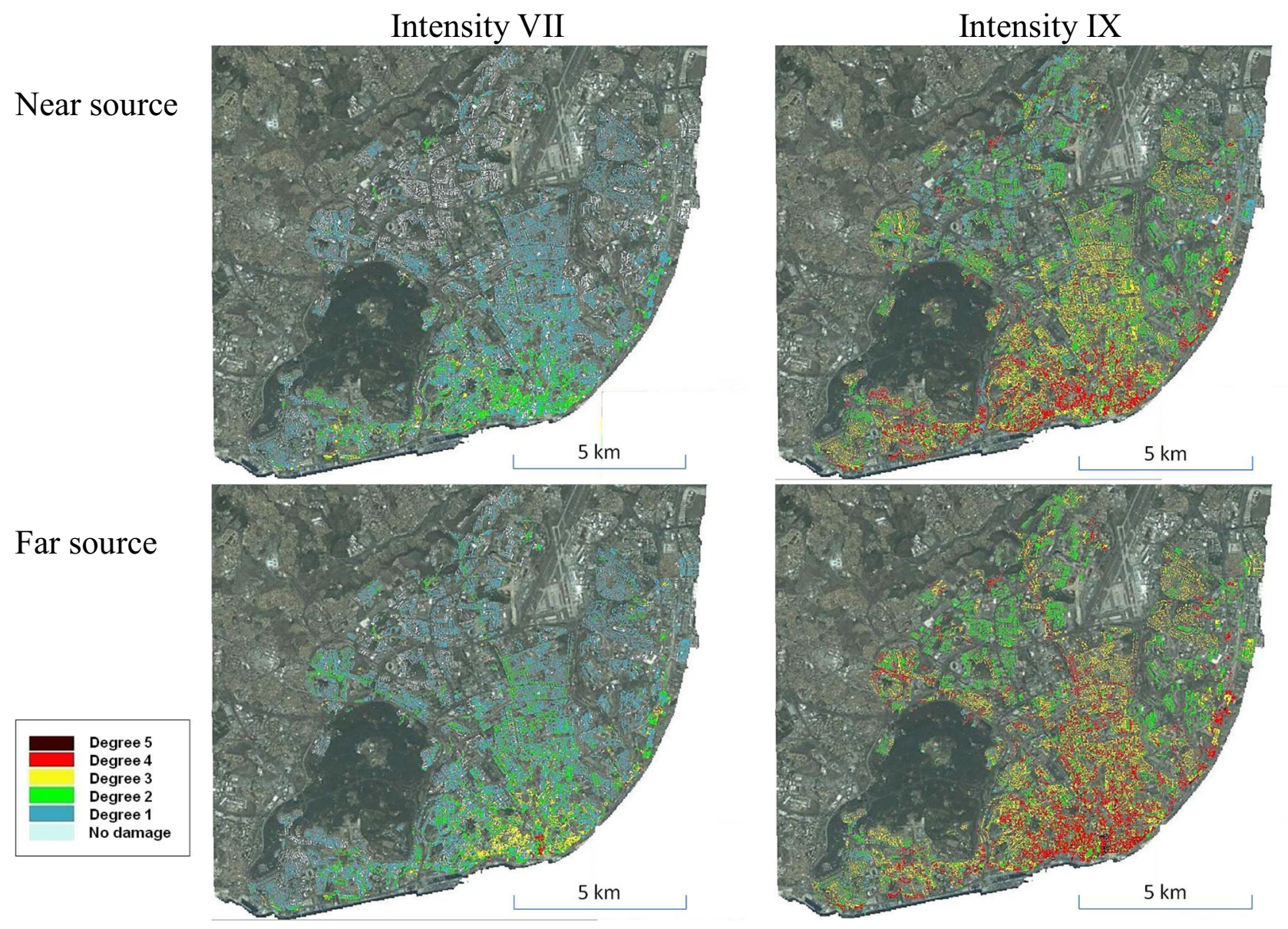

Fig. 5 Building damage spatial distribution for different simulated seismic scenarios in Lisbon. Images are north oriented 
Table 8 Number of buildings and damage degree for the four seismic scenarios

\begin{tabular}{|c|c|c|c|c|}
\hline \multirow[t]{3}{*}{ Damage degree } & \multicolumn{4}{|c|}{ Earthquake type } \\
\hline & \multicolumn{2}{|l|}{ Near source } & \multicolumn{2}{|l|}{ Far source } \\
\hline & Intensity VII & Intensity IX & Intensity VII & Intensity IX \\
\hline 0 & 10,987 & 0 & 5873 & 0 \\
\hline 1 & 28,510 & 5019 & 28,212 & 1189 \\
\hline 2 & 10,708 & 14,397 & 12,131 & 11,261 \\
\hline 3 & 2152 & 19,824 & 5710 & 21,617 \\
\hline 4 & 15 & 12,953 & 446 & 17,250 \\
\hline 5 & 0 & 179 & 0 & 1055 \\
\hline
\end{tabular}

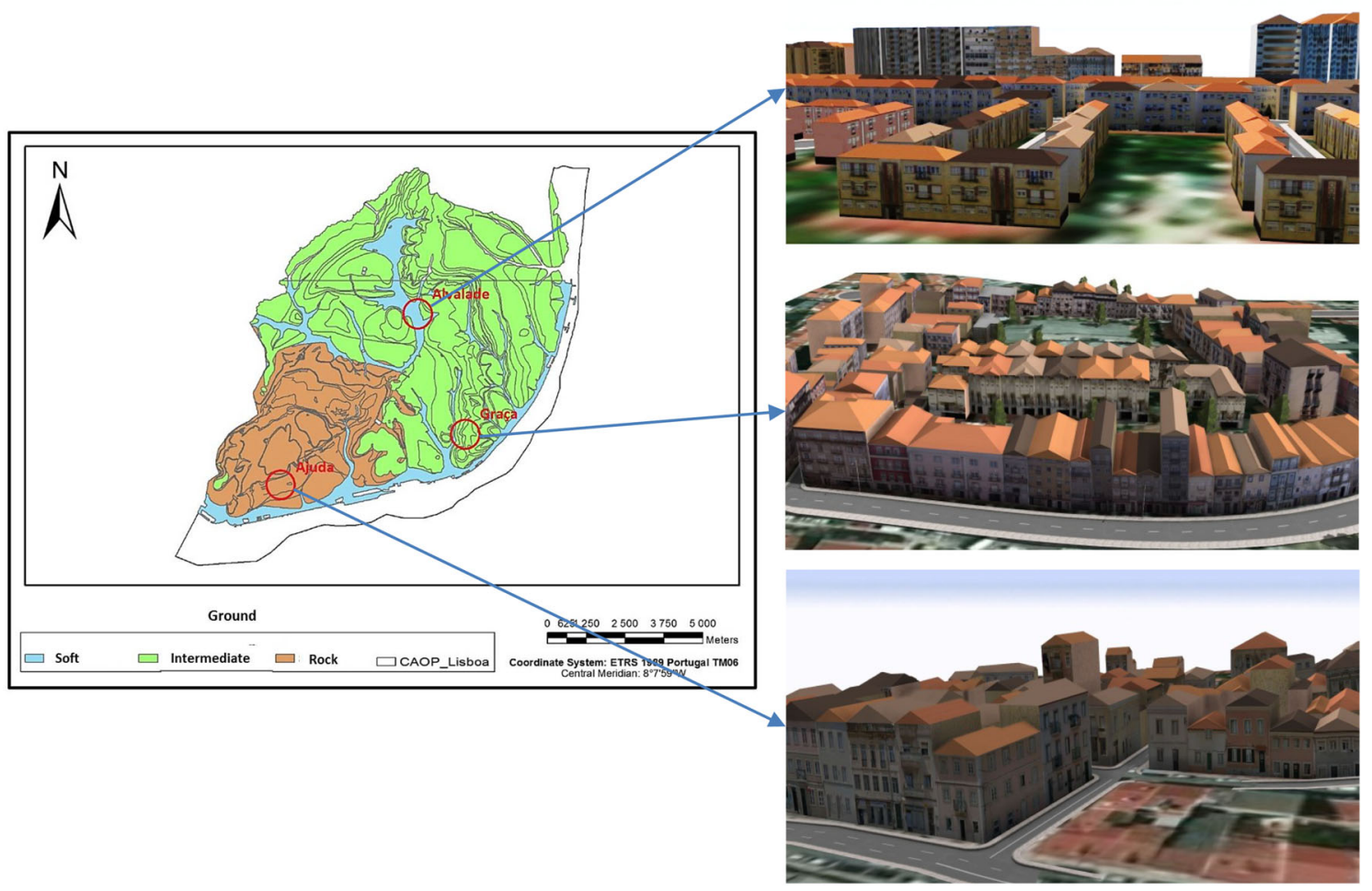

Fig. 6 Pilot areas location and views of the respective 3D model (actual state appearance)

So the three areas chosen include only residential buildings later than 1755: (1) Ajuda, built mainly during the eighteenth century and standing on rock; (2) Graça, constructed in the late eighteenth and early nineteenth centuries and resting on an intermediate soil; and (3) Alvalade, erected from the mid twentieth century and laying on soft soil. The location of the areas in the geological map and an illustration of their actual state 3D model layer are shown in Fig. 6.

The three areas are characterized in Table 9 and, from an urban morphological point of view, they are not dramatically different. The volumetric density and the volumetric heterogeneity are indicators of the built mass in a district. Lower density values indicate urban plans where public spaces are significantly present and lower heterogeneity values reveal more homogeneous buildings in the district area (Santos et al. 2015).

In Fig. 7, we show an example of the analysis that can be done with the 3D city model. The figure displays two scenarios with the color symbology for the Ajuda and Graça areas. The color is automatically assigned to each building according to its estimated damage degree. The same seismic intensity produced by two different sources is considered. It is very clear from this representation that, 
Table 9 Urban morphologic characteristics of the pilot areas

\begin{tabular}{|c|c|c|c|c|c|c|}
\hline Pilot area & $\begin{array}{l}\text { Number of } \\
\text { buildings }\end{array}$ & $\begin{array}{l}\text { Buildings } \\
\text { mean height }(\mathrm{m})\end{array}$ & $\begin{array}{l}\text { Height stand. } \\
\text { dev. }(\mathrm{m})\end{array}$ & $\begin{array}{l}\text { District volumetric } \\
\text { density }\left(\mathrm{m}^{3} / \mathrm{ha}\right)\end{array}$ & $\begin{array}{l}\text { District volumetric } \\
\text { heterogeneity }\left(\mathrm{m}^{3} / \mathrm{ha}\right)\end{array}$ & Epoch \\
\hline Ajuda & 110 & 11 & 3 & 34,177-low & 2-middle & 18th \\
\hline Graça & 120 & 10 & 3 & 44,814—middle & 1.9-middle & 18th-19th \\
\hline Alvalade & 158 & 14 & 6.7 & 44,117_middle & 1.3 -middle & Mid 20th \\
\hline
\end{tabular}

Intensity IX

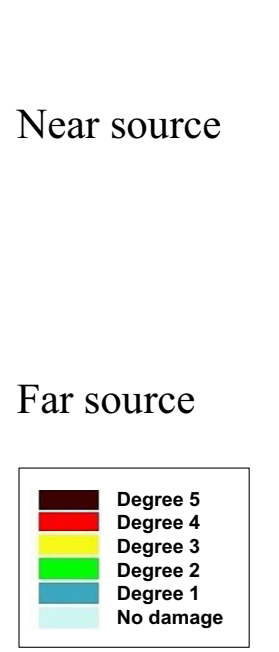

Ajuda

Graça

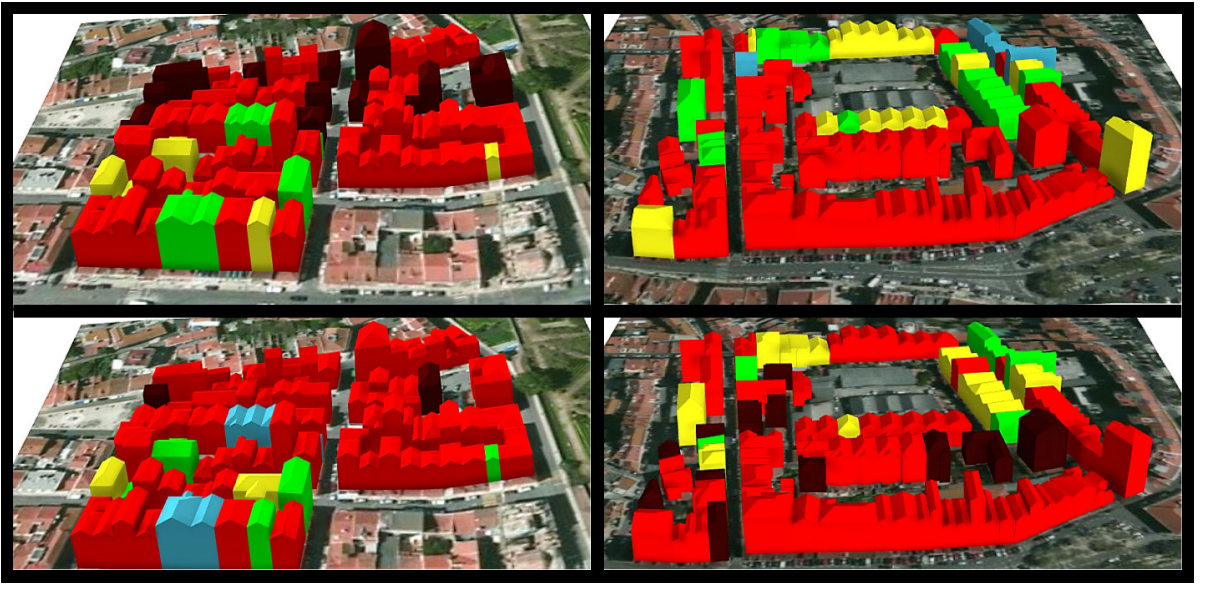

Fig. 7 Comparison between the behavior of buildings in Ajuda and Graça for the same seismic intensity but different sources (color symbology layers)

according to the vulnerability model employed, the two areas react differently to the same type of earthquake. Ajuda suffers more damage (more total collapses) than Graça for a near source, but the situation reverses when the earthquake has origin in a far source.

The reason lies in the amplification effect of the different types of soil, which varies according to the source as expressed by the aggravation factor, $F_{\mathrm{A}}$ (Table 6). This indicates clearly that the vulnerability index of the buildings is not the only conditioner of their damage degree. Higher buildings and those isolated or in a header or corner position in the block are more affected by the earthquake (see Fig. 7, near source in Ajuda and far source in Graça). Identifying the most susceptible buildings is easy by comparing, in the Web Viewer, the layers actual state versus seismic scenario (Fig. 8). The respective attributes also can be queried, an interesting option, for instance, for a stakeholder who needs to invest in seismic improvement measures or for insurance companies. As an example, comparing the vulnerability attributes of the highlighted building in Fig. 8 with those of the left adjacent building, one concludes that the position in block contributed the most to collapse of the highlighted building and non-collapse of the left building, since the other attributes (construction epoch, typology, soil, slope, and so on) are very similar. On the other hand, the corner building in yellow (degree 3), appearing on the right of the seismic scenario, has the same unfavorable position in block. Here are typology (masonry with reinforced concrete floor) and construction epoch (1961-1970) determinant for the estimation of a smaller damage degree.

Table 10 summarizes the results obtained in the seismic simulations for the three pilot areas in terms of percentage of damaged buildings with the indicated damage degree. Bold numbers correspond to the predominant damage degree in the area. Alvalade, the area with more recent structures, seems to behave better than the others, especially in the near source scenarios. The comparison between the 3D models conveys this information very efficiently as demonstrated in Fig. 9, where all three areas are juxtaposed visually. It is evident that the situation is significantly less severe in Alvalade than in the other two areas without the need of statistical interpretation.

\subsection{The Damage Realistic Models}

Color scale symbology is a valuable tool for a prompt interpretation of results. A nonexpert intuitively recognizes 

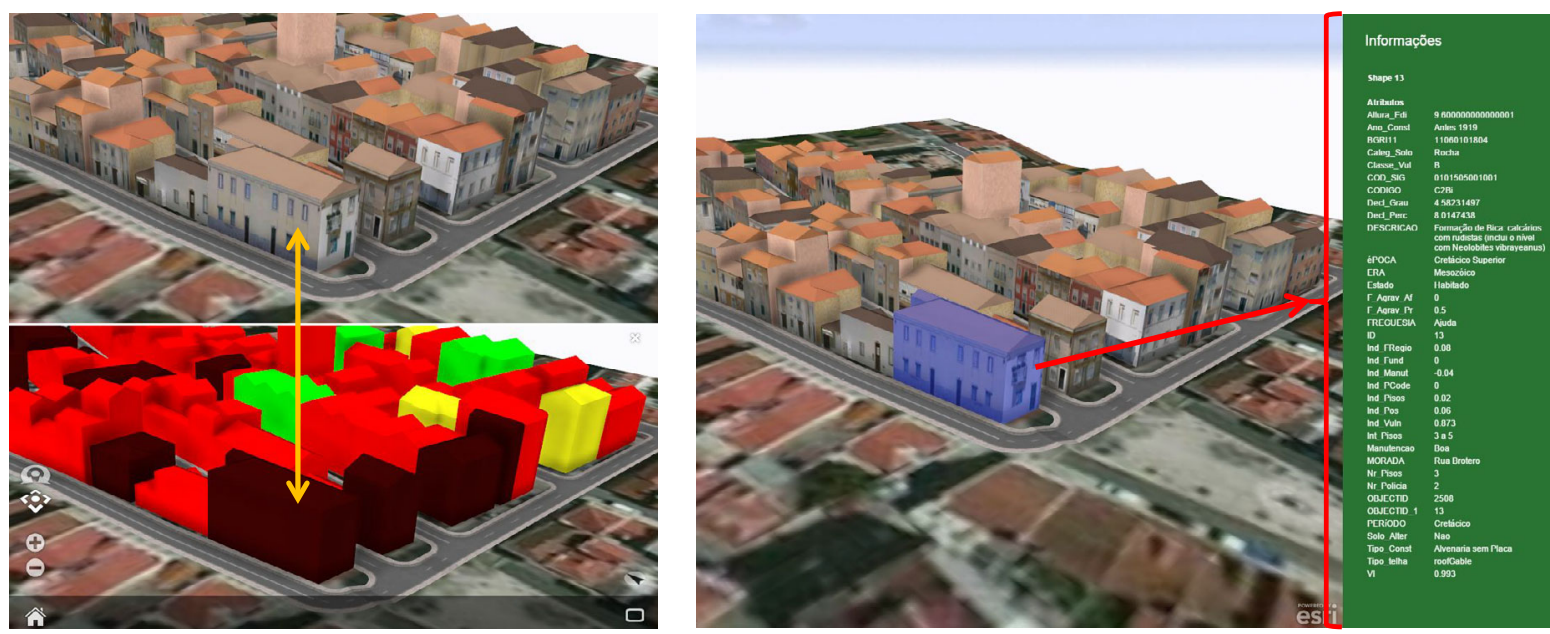

Fig. 8 Identification of a building with potential damage degree 5 (total collapse) in case of a near source earthquake with intensity IX (left). Attribute analysis of the same building (right)

increasing danger in red color shades. Nevertheless, the meaning of the indicated damage degree for the structures cannot be transmitted to the user by the color scale alone. Color just indicates the relative severity of damage; it does not describe what really happens to the building. In this study, an effort was made to transmit the real meaning of a certain damage degree in the $3 \mathrm{D}$ seismic scenarios simulation.
The meaning of the damage scale is well described in EMS98 (Grünthal 1998) for masonry and for reinforced concrete buildings, including a pictorial description (Fig. 10). The scale is meant to be used for damage classification during field surveys after an earthquake. We took advantage of the possibilities of 3D city modeling software to build fictional cities, which has been extensively used in the computer game industry. Particularly important is the

Table 10 Percentage of buildings per damage degree for all seismic scenarios in all pilot areas

\begin{tabular}{|c|c|c|c|c|c|c|}
\hline \multirow{5}{*}{$\begin{array}{l}\text { Pilot Area } \\
\text { Type of soil/ground } \\
\text { Predominant construction epoch } \\
\text { Predominant construction typology }\end{array}$} & \multirow{2}{*}{\multicolumn{2}{|c|}{$\frac{\text { Ajuda }}{\text { Rock }}$}} & \multicolumn{2}{|l|}{ Graça } & \multicolumn{2}{|l|}{ Alvalade } \\
\hline & & & \multicolumn{2}{|c|}{ Intermediate } & \multicolumn{2}{|l|}{ Soft } \\
\hline & \multicolumn{2}{|c|}{ Before 1919} & \multicolumn{2}{|c|}{ Before 1919} & \multicolumn{2}{|c|}{ 1946-1960 } \\
\hline & \multicolumn{2}{|c|}{ Masonry w/o RC floor } & \multicolumn{2}{|c|}{ Masonry w/o RC floor } & \multicolumn{2}{|l|}{$\mathrm{RC}$} \\
\hline & Near $(\%)$ & Far $(\%)$ & Near $(\%)$ & Far $(\%)$ & Near $(\%)$ & $\operatorname{Far}(\%)$ \\
\hline Macro seismic intensity & VII & & & & & \\
\hline \multicolumn{7}{|l|}{ Damage degree } \\
\hline 0 & 0 & 0 & 0 & 0 & 6 & 0 \\
\hline 1 & 12 & 12 & 34 & 22 & 93 & 37 \\
\hline 2 & 52 & 75 & 54 & 50 & 1 & 58 \\
\hline 3 & 36 & 13 & 12 & 28 & 0 & 5 \\
\hline 4 & 0 & 0 & 0 & 0 & 0 & 0 \\
\hline 5 & 0 & 0 & 0 & 0 & 0 & 0 \\
\hline Macro seismic intensity & IX & & & & & \\
\hline \multicolumn{7}{|l|}{ Damage degree } \\
\hline 0 & 0 & 0 & 0 & 0 & 0 & 0 \\
\hline 1 & 0 & 6 & 4 & 0 & 5 & 0 \\
\hline 2 & 7 & 5 & 17 & 6 & 34 & 3 \\
\hline 3 & 5 & 2 & 13 & 15 & 58 & 27 \\
\hline 4 & 75 & 85 & 66 & 67 & 3 & 70 \\
\hline 5 & 13 & 2 & 0 & 12 & 0 & 0 \\
\hline
\end{tabular}

In bold, the percentage corresponding to the predominant damage degree 

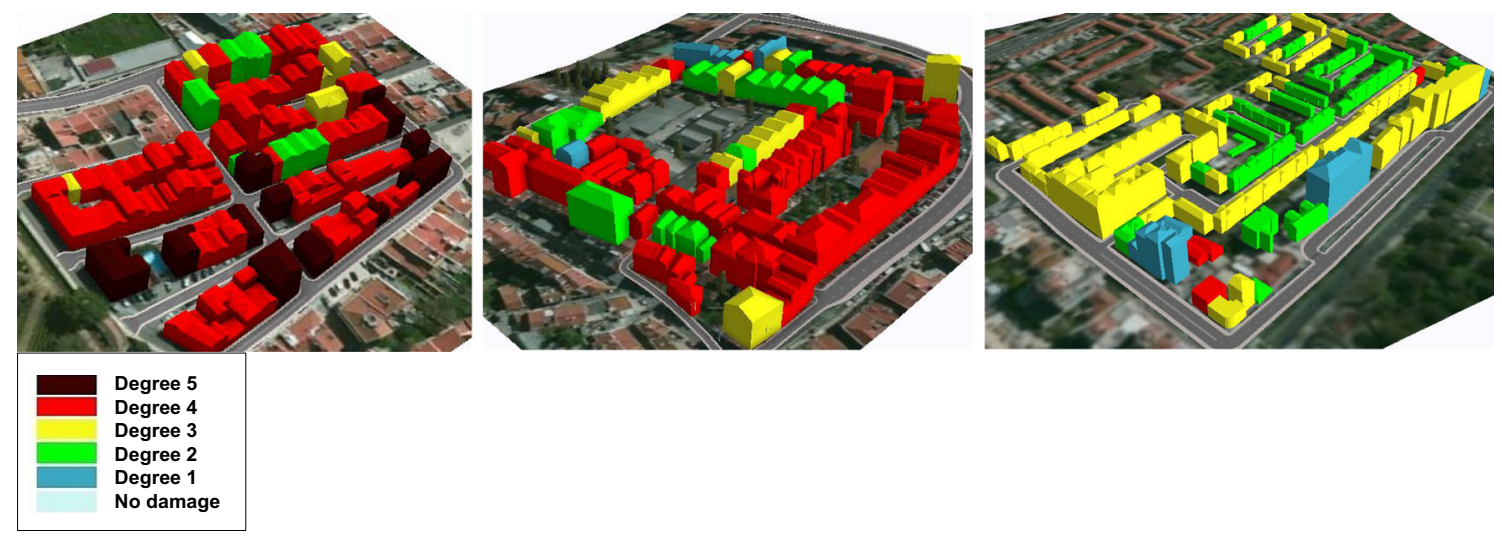

Fig. 9 Simulation of near source earthquake with intensity IX in the pilot areas: Ajuda (left), Graça (middle), and Alvalade (right)

work of Christian Holzer, who developed procedural models of buildings with interactively or randomly changing damage in order to set up a war game scenario (ESRI 2017). We developed damaged building models that adapted to the footprint dimensions and attributes height and number of floors simultaneously. The damage degree associated to the footprint defines the kind of model to apply in a particular scenario.

For this experiment, only models for damage degree 3 and 4 were developed. These models follow distinct concepts for showing damage: (1) changing the building appearance for degree 3; and (2) changing the building geometry for degree 4. Models for degree 1 and 2 can be obtained on the same way as for degree 3: a model that maintains the original building geometry, including the roof, is assigned a texture showing the typical damages for each degree (cracks on the facade, broken windows, holes in the roof, and so on). We decided to divide building facades into the respective number of floors, and to apply a certain texture to the ground floor and repeat a second texture for each of the upper floors. Since the damage models are used as symbols that apply to all footprints with the damage degree in question, the textures originate from photographs of one or two typical buildings in the district that are edited in image processing software to include the damages (Fig. 11 left). Priority was placed on the appearance of the damage for each degree as described in EMS98, not on the resemblance with the actual facade. Nevertheless, for damage degrees up to 3 , it would be possible to associate each footprint in the model database with a set of damaged facade textures created from its actual facade. But without an automated routine, this procedure would be very time and memory consuming when dealing with a large area.

The procedural model for damage degree 4 follows a completely different approach and resorts to 3D models of structural elements (slab, beam, window, door, intact wall, damaged wall, and so on) that are inserted in the building 3D model as implicit geometry objects. The developed procedure is adapted from Holzer's code, available as an example inside CityEngine 2015.1 (ESRI 2017) workspace. The adaption consisted in choosing the relevant elements for a seismic scenario, since the original related to a war game scenario. Adaptations included use of reasonable textures for the walls, which were taken from a typical building in the study area, and directing the procedure to pick the attributes of the actual footprint (dimensions, height, roof type, and number of floors). In general, the adapted Holzer's CGA rule works as follows: each footprint with damage degree 4 is first extruded by the original height and divided in floors, according to the original attribute "number of floors." This division is made at solid model level, not only at facade surface level. Then the walls in each floor are built alternating damaged with nondamaged parts originating from the structural elements 3D models. Also the interior of each floor gets a floor texture, and damaged or nondamaged 3D beams are included. Damage is offset in the front facade from floor to floor in order to create the impression of damage continuity between floors (Fig. 11 right). The proof of concept was successful and the developed procedure creates automatically a damaged 3D city landscape according to calculated parameters for the footprints. We were guided by the damage degree pictures in Fig. 10 originating from EMS98 (Grünthal 1998). The procedure can be adapted to other seismic damage, for instance typical damage usually observed in soft floors. A rule deciding which of these models (appearance or geometry change) to use according to the damage degree associated to the footprint was applied in order to generate a damage realistic layer (Fig. 12). 


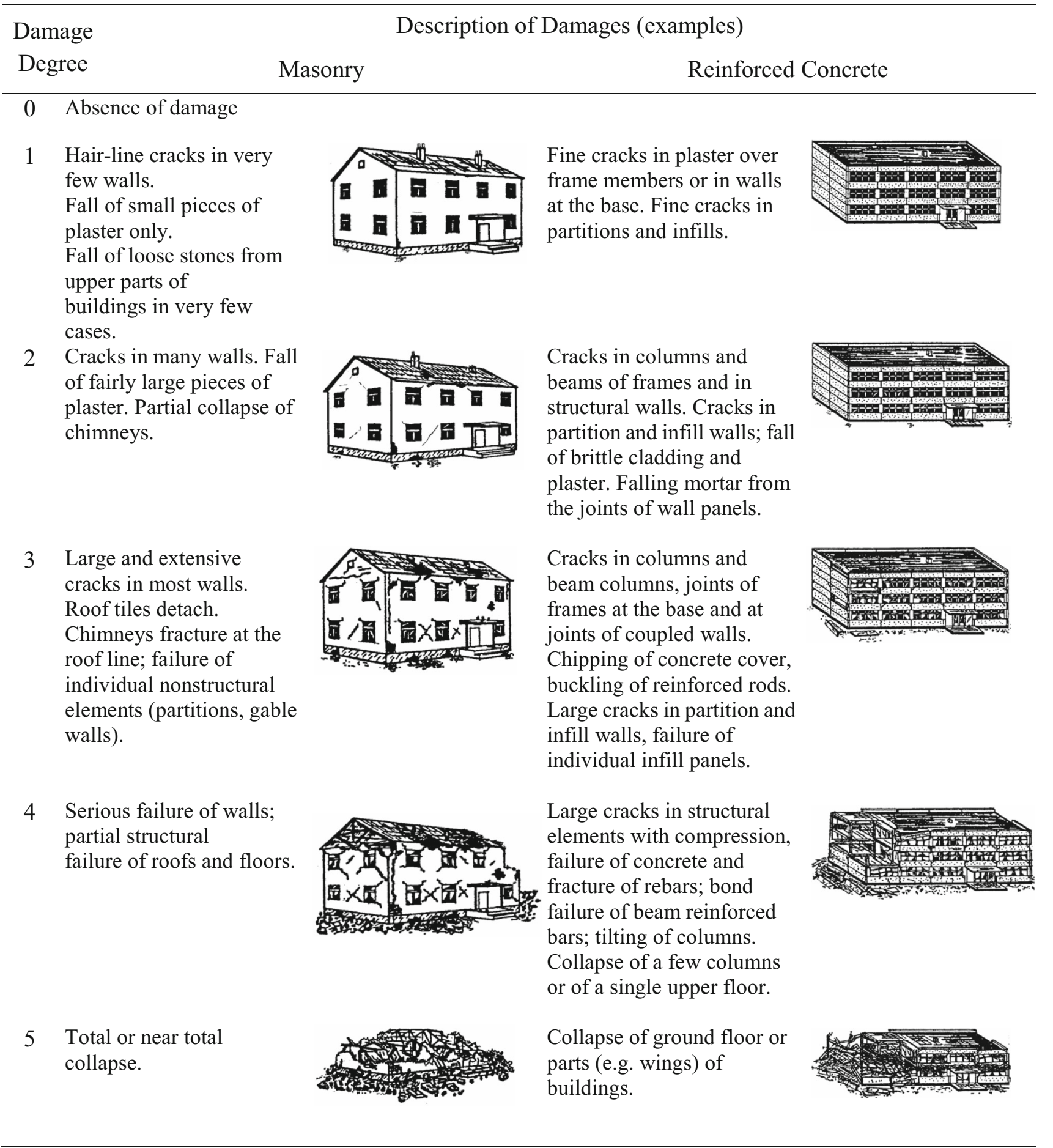

Fig. 10 EMS98 Damage scale description for masonary and reinforced concrete buildings. Source: Adapted from Grünthal (1998)

Since these models must contain interior spaces (floors, some interior walls, beams), the respective layer is much heavier than the layers containing only color symbology or facades. Nevertheless, a representation like this can be very useful in supporting seismic risk prevention awareness campaigns on TV and in the internet. Common citizens who never experienced an earthquake are more likely to react to 3D scenes of their simulated damaged neighborhood and be ready for taking preventive measures, than to colored maps with scientific results or pictures of earthquake damage occurred elsewhere. Also local authorities can be moved by these simulations to invest, for instance, in retrofitting measures in the most vulnerable buildings of their jurisdiction. 


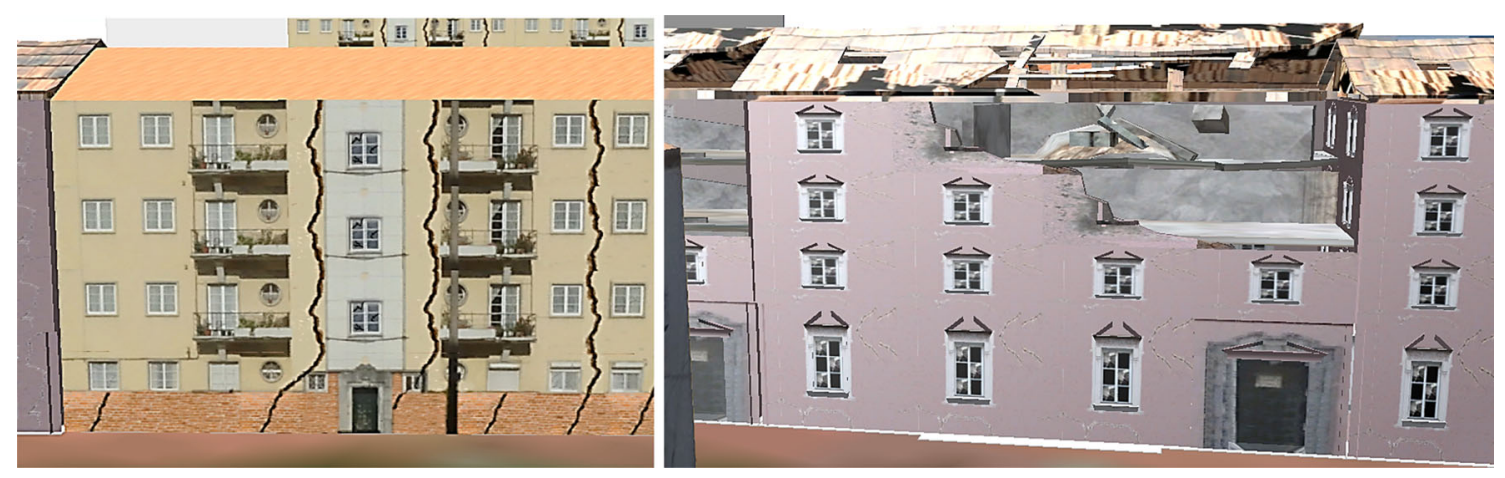

Fig. 11 Models textured according to damage degrees 3 (left) and 4 (right)

Fig. 12 Damage realistic scenario-Alvalade, far source, intensity IX

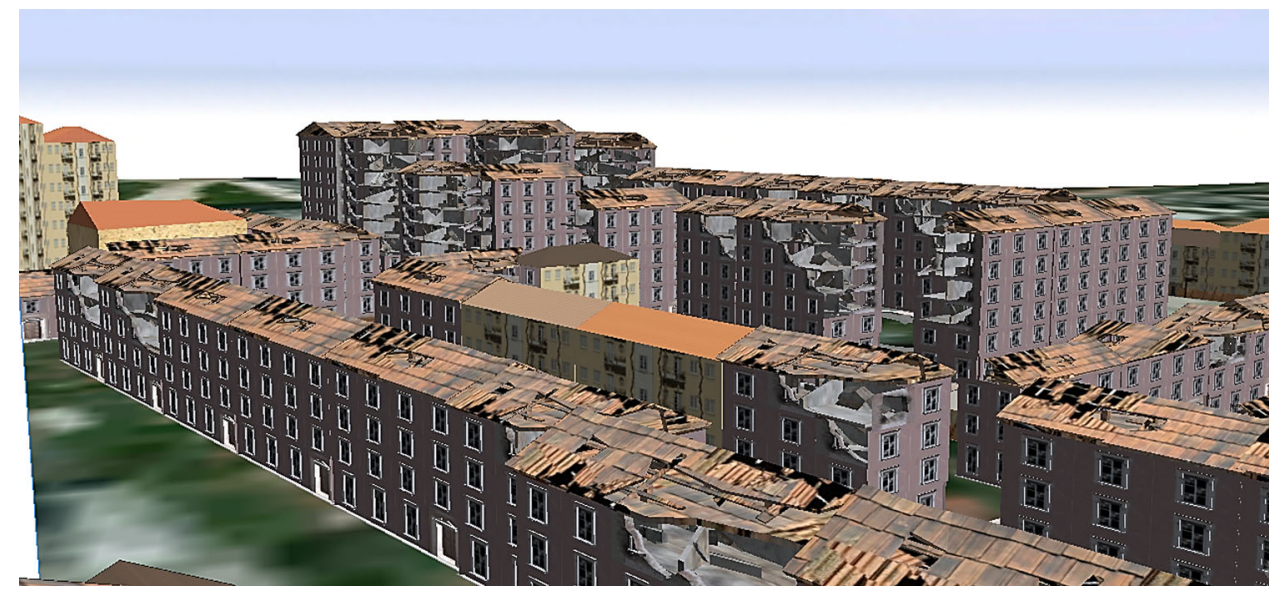

\section{Conclusion}

Studies on the seismic vulnerability of city buildings can profit from the use of 3DCM especially when city databases are detailed to the scale of a building. LoD1 is sufficient for modeling extended areas, as in the case of the whole municipality of Lisbon, but LoD2 gives the buildings more recognition value, which can be an advantage in emergency decision making. LoD2 was used in this study for three pilot areas. The whole methodology could be applied to other cities if the regional vulnerability factor and the aggravation factor are defined.

3D scenarios organized as shown in this work, with an actual state layer that contains geometric models of the buildings with actual facades, and several layers that show the result of seismic simulations, can be easily published on the Web or through a local server. These models can be shared through a Web link with stakeholders for further analysis without the need for software installation.

ArcGIS 10.3 and CityEngine 2015.1 together with the CityEngine Web Viewer have fulfilled all requirements for a study of this nature as long as the area dimensions and the complexity of the models stay limited. For the whole municipality, the solution required us to program CGA rules in CityEngine, to import those rules in ArcGIS Pro in order to generate the $3 \mathrm{D}$ scenarios, and later to export the layers to a local server managed through Portal for ArcGIS. Open source alternatives were not tested.

Attributes of each object are accessible in every layer and include building attributes (address, number of floors, roof type, construction epoch, construction type, and so on), soil attributes (geology, lithology, landfill depth, among others), and vulnerability modifying factors (maintenance state, position in block, and so on). The total vulnerability index of each object is accessible. Simple queries can be made to all the attributes existing in the database, which is relevant for stakeholders who are interested in analyzing the seismic behavior patterns of buildings.

The visual analysis of seismic simulation results is very simplified through the maintenance of building geometry and the application of color symbology to the objects, which uses the estimated damage degree in the EMS98 scale as proposed in this work. The relation between seismic scenario and real objects is easily obtained through comparison in the Web viewer between the scenario and the actual state layer. This operation (swipe view) is a standard in the CityEngine Web Viewer. 
Since calculations for some fields in the database are performed by means of external scripts, simulations in the model to test its sensitivity to the parameters can be easily done. Each change in the vulnerability parameters and/or aggravation factors will influence the outcome of the damage scenario. When applied to urban regions where recent earthquakes have occurred and for which damages are photo documented, our method can be used as a tool for calibrating the vulnerability model by comparing the simulated damage degree with the damage that actually occurred.

Finally, damage realistic 3D scenarios, originally designed for fictional game environments and adapted here for eventual reality, are striking tools that transform the text and visual description of the EMS98 damage scale into a believable 3D damage scene. This technique may be relevant in awareness campaigns at several levels, including use to impress ordinary citizens, local authorities, and national politicians with the importance of preparation for potential future emergencies.

Acknowledgements This work was partially supported by the Project FCT UID/GEO/50019/2013-Instituto Dom Luiz.

Open Access This article is distributed under the terms of the Creative Commons Attribution 4.0 International License (http://crea tivecommons.org/licenses/by/4.0/), which permits unrestricted use, distribution, and reproduction in any medium, provided you give appropriate credit to the original author(s) and the source, provide a link to the Creative Commons license, and indicate if changes were made.

\section{References}

Almeida, F.M. 1986. Geological map of Lisbon Council 1:10,000, Serviços Geológicos de Portugal, Lisbon (in Portuguese).

ArcGIS. 2017. Web site. http://doc.arcgis.com/en/arcgis-online/refer ence/about-cityengine-web-viewer.htm. Accessed 7 Sept 2017.

Bakir, S., H. Sukuoglu, and T. Yilmaz. 2002. An overview of local site effects and the associated building damage in Adapazari during the 17 August 1999 Izmit earthquake. Bulletin of the Seismological Society of America 92(1): 509-526.

Borcherdt, R. 1970. Effects of local geology on ground motion near San Francisco Bay. Bulletin of the Seismological Society of America 60(1): 29-61.

CityGML. 2017. Web site. http://www.opengeospatial.org/standards/ citygml. Accessed 7 Sept 2017.

Dias, P. 2013. Elaboration of a Lisbon landfill map using LiDAR and aerial photogrammetry. (Elaboração de uma carta de aterros da cidade de Lisboa por LiDAR e Fotogrametria aérea). MSc. thesis. Faculdade de Ciências, Universidade de Lisboa, Lisbon, Portugal. http://repositorio.ul.pt/bitstream/10451/9878/1/ ulfc105777_tm_Pedro_Dias.pdf. Accessed 7 Sept 2017 (in Portuguese with English abstract).

ESRI (Environmental Systems Research Institute). 2017. Web site. http://www.esri.com/products. Accessed 7 Sept 2017.

Fritsche, S., D. Fah, B. Steiner, and D. Giardini. 2009. Damage field and site effects: Multidisciplinary studies of the 1964 earthquake series in Central Switzerland. Natural Hazards 48(2): 203-227.
Giammarinaro, S., A. Tertulliani, G. Galli, and M. Leta. 2005. Investigation of surface geology and intensity variability in the Palermo, Italy, urban area after the 6 September 2002 earthquake. Bulletin of the Seismological Society of America 95(6): 2318-2327.

Grünthal, G. 1998. European macroseismic scale 1998. Luxembourg: Centre Européen de Géodynamique et de Séismologie. http:// www.franceseisme.fr/EMS98_Original_english.pdf. Accessed 7 Sept 2017.

Idriss, I.M. 1990. Influence of local site conditions on earthquake ground motions. In Proceedings of the 4th US National Conference on Earthquake Engineering, 20-24 May, Palm Springs, California, U.S.A., 55-57.

INE (Instituto Nacional de Estatística / National Statistics Institute). 2004. Urban system: Areas of influence and functional marginality: Central region (Sistema urbano: áreas de influência e marginalidade funcional: região Centro). Lisbon: Instituto Nacional de Estatística. http://www.ine.pt/xportal/xmain?xpid= INE\&xpgid=ine_publicacoes\&PUBLICACOESpub_boui= 11355196\&PUBLICACOEStema $=55481 \&$ PUBLICACOES modo=2. Accessed 12 Sept 2017 (in Portuguese).

INE (Instituto Nacional de Estatística / National Statistics Institute). 2011. Census 2011. http://mapas.ine.pt/map.phtml. Accessed 7 Sept 2017.

Kemec, S., S. Zlatanova, and S. Duzgun. 2009. Selecting 3d urban visualisation models for disaster management: A rule-based approach. In Proceedings of the International Emergency Management Society Annual Conference, 9-11 June, Istanbul, Turkey, 99-110.

Kemec, S., S. Zlatanova, and S. Duzgun. 2010. A framework for defining a 3D model in support of risk management. In Geographic information and cartography for risk and crisis management, ed. M. Konecny, S. Zlatanova, and T. Bandrova, 69-82. New York: Springer.

Milutinovic, Z., and G. Trendafiloski. 2003. WP04: Vulnerability of current buildings. RISK-UE Project of the EC: An advanced Approach to Earthquake Risk Scenarios with Applications to Different European Towns. EVK4-CT-2000-00014. https:// www.dropbox.com/s/nu7rvvt7t7ii1lv/Milutinovic\%26Trendafi loski2003_RISK-UE_WP4.pdf?dl=0. Accessed 7 Sept 2017.

Navarro, M., A. García-Jerez, F.J. Alcalá, F. Vidal, C. Aranda, and T. Enomoto. 2012. Analysis of site effects, building response and damage distribution observed due the 2011 Lorca, Spain, earthquake. In Proceedings of the 15th World Conference on Earthquake Engineering, 24-28 September, Lisbon, Portugal.

Navarro, M., F. Vidal, T. Enomoto, F. Alcala, A. García- Jerez, N. Abeki, and F. Luzón. 2009. Correlation between site effects and damage distribution observed during moderate earthquakes in SE Spain. In Proceedings of the 8th International Workshop on Seismic Microzoning and Risk Reduction, 15-18 March, Almeria, Spain, University of Almería. http://www.ual.es/Congresos/ 8IWSMRR. Accessed 12 Sept 2017.

Poljansek, K., F. Bono, and E. Gutiérrez. 2010. GIS-based method to assess seismic vulnerability of interconnected infrastructure- $\mathrm{A}$ case of EU gas and electricity networks. JRC Scientific and Technical Reports, European Commission. EUR 24275 EN2010.

Rashed, T., and J. Weeks. 2003. Assessing vulnerability to earthquake hazards through spatial multicriteria analysis of urban areas. International Journal of Geographical Information Science 17(6): 547-576.

Rezaie, F., and M. Panahi. 2015. GIS modeling of seismic vulnerability of residential fabrics considering geotechnical, structural, social and physical distance indicators in Tehran using multicriteria decision-making techniques. Natural Hazards and Earth System Sciences 15(3): 461-474. 
Santos, T., A.M. Rodrigues, and F. Ramalhete. 2015. Assessing patterns of urban transmutation through 3D geographical modelling and using historical micro-datasets. In Computational Science and Its Applications-ICCSA 2015, ed. O. Gervasi, B. Murgante, S. Misra, M.L. Gavrilova, A.M.A.C. Rocha, C.M. Torre, D. Taniar, and B.O. Apduhan, Part I, 32-44. Cham: Springer.

Sousa, M. 2006. Seismic risk in continental Portugal (Risco Sísmico em Portugal Continental). Ph.D. thesis. Instituto Superior Técnico, Universidade de Lisboa, Lisbon, Portugal (in Portuguese with English Abstract).

Teves-Costa, P., and E. Barreira. 2012. Damage scenarios in Lisbon using RISK-UE approach. In Proceedings of the 15th World Conference on Earthquake Engineering, 24-28 September, Lisbon, Portugal.

Teves-Costa, P., I.M. Almeida, and I.N. Rodrigues. 2012. Distribution of peak and spectral frequencies in Lisbon. Application of geological and geotechnical data. In Proceedings of the 15th World Conference on Earthquake Engineering, 24-28 September, Lisbon, Portugal.

Teves-Costa, P., I.M. Almeida, I. Rodrigues, R. Matildes, and C. Pinto. 2014. Geotechnical characterization and seismic response of shallow geological formations in downtown Lisbon. Annals of Geophysics 57(4): S0436.

Teves-Costa, P., E. Barreira, and R. Omira. 2011. Synthesis map of seismic risk (Mapa síntese de risco sísmico). Deliverable IE23. Project "Evaluation of natural and technological risks in the city of Lisbon" (Avaliação de riscos naturais e tecnológicos na cidade de Lisboa), Fundação da Faculdade de Ciências da Universidade de Lisboa (in Portuguese).

Zlatanova, S. 2008. SII for emergency response: The 3d challenges. The International Archives of the Photogrammetry, Remote Sensing and Spatial Information Sciences 37 (Part B4): 1631-1637. 